\title{
Article
}

\section{'In these streets': The saliency of place in an alternative black mental health resource centre}

Wainwright, John Peter, Mckeown, Michael and Kinney, Malcolm Available at http://clok.uclan.ac.uk/30481/

Wainwright, John Peter ORCID: 0000-0002-8190-0144, Mckeown, Michael ORCID: 0000-0003-0235-1923 and Kinney, Malcolm (2019) 'In these streets': The saliency of place in an alternative black mental health resource centre. International Journal of Human Rights in Healthcare, 13 (1). pp. 31-44.

It is advisable to refer to the publisher's version if you intend to cite from the work. http://dx.doi.org/10.1108/JHRH-08-2019-0062

For more information about UCLan's research in this area go to http://www.uclan.ac.uk/researchgroups/ and search for <name of research Group>.

For information about Research generally at UCLan please go to http://www.uclan.ac.uk/research/

All outputs in CLoK are protected by Intellectual Property Rights law, including Copyright law. Copyright, IPR and Moral Rights for the works on this site are retained by the individual authors and/or other copyright owners. Terms and conditions for use of this material are defined in the policies page.

\section{CLoK}

Central Lancashire online Knowledge www.clok.uclan.ac.uk

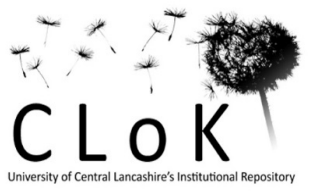




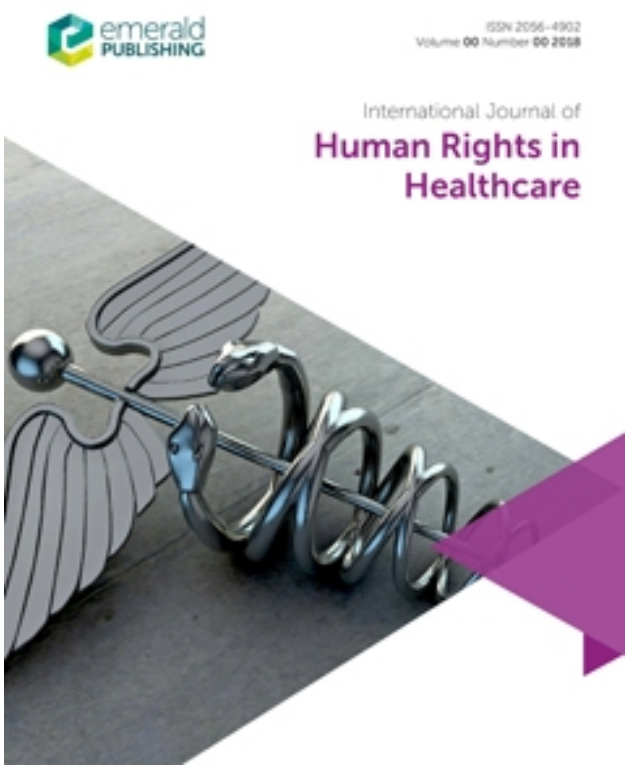

\section{'In these streets': The saliency of place in an alternative black mental health resource centre}

\begin{tabular}{|r|l|}
\hline Journal: & International Journal of Human Rights in Healthcare \\
\hline Manuscript ID & IJHRH-08-2019-0062.R1 \\
\hline Manuscript Type: & Research Paper \\
\hline Keywords: & mental health, race, place and space, sociology, qualitative methods \\
\hline \multicolumn{2}{|l}{} \\
\end{tabular}

\section{SCHOLARONE ${ }^{\text {M }}$ \\ Manuscripts}


'In these streets': The saliency of place in an alternative black mental health resource centre

\section{Abstract \\ Purpose}

This study explored experiences of survivors of the mental health system regularly attending a mental health resource centre predominantly but not exclusively focused on needs of the BAME community.

\section{Methodology}

Twenty-five participants took part in a qualitative research study regarding their experiences of mental health and racism, alternative mental health support, and struggles in the local black community.

\section{Findings}

Issues of race, place and space were central to the experiences of BAME mental health survivors. Participants emphasised the importance of place based support in their everyday life, with the service provided engendering a sense of belonging conducive to coping with various struggles. Race and racism were also central to these daily struggles and the place of Liverpool 8 was at the core of notions of identity and belonging. The space within the centre provided a sanctuary from the combined discriminations and exclusions attendant on being BAME survivors of the mental health system.

\section{$\underline{\text { Implications }}$}

Place is salient to understanding the intersecting identities/experience of racism and mental health discrimination, constituting the basis for a concept of placism; associated with exclusions from feeling safe and included in everyday public places (including within the Black community) with the exception of the welcoming and unconditionally accepting space of the centre. Attention to matters of place and space appears crucial to the articulation of appropriate support.

\section{Originality}


This paper is the first to inquire into place based experiences of alternative black mental health support. Placism is a novel construct that merits further inquiry and theoretical development.

Key words: mental health, race and ethnicity, place and space, sociology, qualitative methods.

\section{What is known about this topic}

- Place is associated with ethnicity and disadvantage in health and mental health contexts.

- Place based affinities are linked to positive aspects of identity.

- Individuals from BAME communities experience various forms of anomalous treatment within mental health services.

- Alternative, culturally sensitive, mental health care has been advocated for but there is a dearth of evidence accounting for the value of such provision.

\section{What this paper adds}

- Qualitative evidence for the value of and appreciation for alternative, self-organised BAME mental health facilities.

- This appreciation continues to be contrasted with negative experiences in the mainstream, confirming anomalies in care and treatment of BAME service users in the present.

- Demonstration of the importance of considering place in the context of making sense of patterns of intersecting disadvantage and the saliency of place for appreciation for alternative provision of support.

\section{Introduction}

This paper draws upon analysis of qualitative data produced by members (service users) of Mary Seacole House (MSH), an alternative BAME resource centre, as part of a wider project 
designed to organise thinking and contributions for future service planning. The findings presented here are limited to understandings of place and space articulated by the participating members, which are crucial in making sense of the value of this community mental health facility within the long-standing Liverpool black community where it is situated. Positive identity claims, in contrast to negative impacts of racism and mental health stigma, are realised within the protected space of self-organised, black mental health support strongly attached to its geographical location. In the paper we use the terminology of 'black' to refer inclusively to various BAME groups; we also refer to a 'black community', or 'The Community' of Liverpool 8 in a similarly inclusive way, reflecting the significant ethnic diversity of residents of the locality.

\section{Ethnic diversity and disadvantage in mental health}

Disadvantage is linked to ethnicity and place for both physical and mental health (Walker et al. 2016) with racism implicated in outcomes (Paradies et al. 2015). Annual reviews of mental health care (e.g. Care Quality Commission 2018) revisit patterns of disadvantage reported in earlier studies, implicated in the UK review of mental health legislation (Department of Health and Social Care 2018). This confirms ethnic minorities, particularly black African and black Caribbean men, are disproportionately located in inpatient services and coercively detained (Singh et al. 2007; Gajwani et al. 2016). Pathways into care are more adverse (Morgan et al., 2004; Sass et al., 2009; Bhui et al. 2015), often involving police or the courts (Rogers and Faulkner, 1987; Boast and Chesterman 1995). Access to psychotherapy is disproportionately low while use of physical treatments is high (Littlewood and Cross, 1980; Chen, Harrison and Standen, 1991; Gudjonsson et al. 2000; Raleigh et al. 2007), and BAME individuals are concentrated in increasingly restrictive environments (Moodley and Thorneycroft, 1988; author's own, 2001; Leese et al. 2006). Despite policy emphasising recovery, user involvement and self-determination, BAME communities struggle to be heard (DoH, 2005; DoHSC, 2018).

\section{Self-Organised Alternatives}


The organised service user movement has also been criticised for insufficiently diverse membership and constituent groups (Wallcraft, Read and Sweeney 2003). More positively, initiatives like the Black Spaces Project support black service user voice and needs (Christie and Hill, 2003; Wright and Hutnik, 2004; BME Voices, 2019). Relatedly, MIND the national mental health charity, published Diverse Minds in recognition of racial disadvantage across mental health care. Fernando (2005) discusses a number of alternative approaches to mental health care and support emerging in the voluntary sector and certain statutory sector developments such as the ground breaking Sharing Voices community development project in Bradford (Seebohm et al, 2005; Thomas et al. 2006; Thomas 2014). Significant self-organised initiatives for alternative care and advocacy were established in places such as Brixton, Hackney, Manchester and Liverpool (Francis, 1991; Christie and Hill 2003), yet:

No clear-cut single 'good practice model' for multicultural services has emerged in the UK (Fernando 2005: 427).

The most recent UK government response to anomalous mental health care provision, the Delivering Race Equality programme (NIMHE, 2003; DoH, 2005), though wedded to community engagement ideals, failed to properly re-energise alternative services by focusing efforts on transforming attitudes and practices in the mainstream (Fernando, 2010; Bhui et al. 2012; Thomas 2014).

MSH, one exemplar alternative, is a long established provider of services for BAME mental health users in Merseyside, celebrating its 25th anniversary in 2017. Emerging through mental health survivor and community activism, MSH represents an historical and contemporary challenge to inequities in the mental health system (GCMHG 2018). MSH is strategically managed by a Board of Trustees representative of the Liverpool 8 community and receives funding from a combination of sources, including Liverpool City Council. Processes of member involvement support day to day management of MSH and the nature of activities supported. Services provided by MSH are responsive to the demographic characteristics of Liverpool's shifting patterns of cultural diversity, based upon local intelligence and community relationships. MSH does not employ community development 
workers, but has close working relationships with city-wide CDWs employed by the NHS. The need for such distinct services, purposively located in place and space, has arguably never been more important; confirmed by new influxes of refugees and asylum seekers finding tangible refuge and asylum within MSH. Nevertheless, such initiatives are precarious, compounded by austerity squeezed funding, and the insecurities of funding create occasional dilemmas of accountability, with an aspirational commitment to be accountable to members and the community in tension with funders' expectations.

\section{Race, place and space}

Benefits have been noted accruing from positive affinity for home and local area, reflected in various health, wellbeing and quality of life outcomes, social capital and civic/community engagement (Harris et al, 1995; Mesch and Manor, 1998; Brown et al. 2002; Ziersch et al., 2005; Tartaglia, 2013). Attachment to place is associated with better mental health, including for BAME communities, and can mediate adverse effects of the physical and social environment (Becares and Nazroo, 2013; Marcheshci et al., 2015). Kalathil et al (2011) have demonstrated the important of place and space in a study of women of South Asian, Black African and Caribbean heritage.

Conversely, dislike of place has negative outcomes (Stokols and Shumaker 1982). Negative effects of place attachment can involve antipathy to newcomers or people perceived as different (Fried 2000). Beyond interests in spatiality and social dimensions of cities, geographers have articulated a small but growing field of study concerned with mental health (Parr 1997, 2000; Wolch and Philo 2000). This moves beyond accounts of place restricted to aggregates of inter-personal relationships to discern an interplay between people and the material fabric of cities, their streets, parks and other spaces, in ways that open up or close down propensity for communal, social or political action (Amin 2008).

When considering salience of place for residents of a neighbourhood or city it is useful to distinguish between affinities for place (Low and Altman, 1992) and the extent to which 
place influences identity (Proshansky et al, 1983). Both affinity for place and place identity are established in relation to the physical environment and the interactions that take place there (Bernardo and Palma-Oliveira, 2005). Hall (1998) reminds us identity is not fixed, being perpetually produced and reproduced within prevailing systems of representation. With regards to the city of Liverpool as a whole, Boland (2008a, 2008b) acknowledges different internally and externally perceived notions of Liverpool identity creating distinctly social and spatial imaginations. 'Scouse' pride contrasts with negative media portrayal of disadvantage and supposed criminality. Scouse identity has been associated with an edgy, humorous, working class character that readily translates into urban pride and rebelliousness; for example, in resistance to perceived slights or unfairness seen to be heaped on the city by external forces, such as employers or government (see Beynon, 1984; Taaffe and Mulhearn 1988).

Consideration of Liverpool arguably offers insight into a complex inter-relationship between place based affinities and identities at the neighbourhood and city levels. Liverpool or Scouse identity, hence, is complexly worked out in relation to the micro-spatial divisions of the city and histories of disadvantage and exclusions, with race a crucial influence. These matters of identity are further complicated by consideration of intersectionality (Nayak \& Robbins, 2018, Siddiqui \&Thiara, 2018, Crenshaw, 2019). Within such a frame, Liverpool, compared with the rest of the UK, represents a unique confluence of geographic, historical and racialized social and economic relations, with a long-established, mainly indigenous black population, of various ethnicities, and relatively high proportion of dual heritage individuals (Law and Henfry, 1981; Ben-Tovim, et al.1986; Liverpool Black Caucus, 1986; Small 1991). These socio-historical circumstances have also influenced patterns of health and mental health disadvantage (Torkington 1983).

\section{Liverpool 8}

Lashua (2015: 45) suggests 'Liverpool 8 ... is the traditional socio-geographic heart of Liverpool's black communities', but associated with the 1981 riots, and negatively perceived in the wider area of Merseyside (Gifford et al. 1989; Ben-Tovim, 1997). Exacerbating this 
experience of exclusion, the wider importance of the Black community in the city is often denied, including contributions to social, cultural and economic developments, such as the music scene; a huge part of the city 'brand'. Indeed, Liverpool's black community has experienced continuous exposure to and struggle against racism, discrimination and sundry exclusions (Zack-Williams, 1997: 529):

The perception of Black people as outsiders has continued to define the daily reality of life in Liverpool and they continue to be marginalized from the central decisionmaking process.

Zack-Williams (1997: 541) concludes, 'despite its permanency, the black community of Liverpool 8 can be viewed as one of the most historically deprived in Britain, and more or less constitutes an internal colony with lack of control over its own resources and destiny'.

Patterns of exclusion and refused entry to mainstream white clubs in the city centre led to the development of a vibrant set of social clubs in Liverpool 8 in the 1960s, attached to community identities and cultural heritage (Small 1991). Waves of privatisations and restructuring of housing stock ownership significantly altered the sense of place, linked to impoverishment and the eventual closure of many of the clubs together with some dispersal of communities and residents (Lashua 2015). The leaching of economic resources from Liverpool 8 was a significant precipitator of the aforementioned riots (see Ben-Tovim, 1986; Gifford et al, 1989). In terms of simple representation, there is little to suggest the picture has changed in intervening decades. Arguably, this marginalisation of voice extends into the micro-democracies of statutory mental health services, despite recent vogues for userinvolvement.

Geographies of racism, underpinning segregated patterns of residence and other exclusions, are crucial in understanding matters of identity within specific Liverpool neighbourhoods such as Liverpool 8 (Small 1991). Liverpool black residents, thus, have ambivalence to the 
City and scouse identity, yet are definitely scouse with regard to geography and accent, performing a scouse identity whilst maintaining other heritage, cultural and place attachments, including to Liverpool 8 (Boland 2010). Boland (2010) draws attention to the idea that Liverpool 8 exemplifies an imagined community, in that belonging to 'The Community' need not require knowing all others in the community; rather there is a strong sense of common bond. This certainly involves attachments to the place and community that is Liverpool 8, and notable places within Liverpool 8 boundaries, such as MSH.

\section{Methods}

We aimed to explore participants' experiences of range, depth and quality of services provided by $\mathrm{MSH}$, and to initiate thinking about possible future service developments. A generally appreciative (Cooperrider \& Srivastva, 1987) stance was taken to elicit views on perceived good practice/support from the different services at MSH, the extent to which these services might be valued and reasons why. We attended MSH prior to data collection to introduce ourselves and engage with participants about our purpose. With a purposive approach to broadly representing the diversity of MSH membership, twenty-five members of MSH were included in the sample, comprising eleven women and fourteen men; all volunteered following briefing meetings and/or follow up queries from MSH staff. Women participants comprised the following ethnicities; eight Pakistani/South Asian heritage, two African/Caribbean dual heritage and one white British. Eleven of the fourteen men were African/Caribbean-dual heritage or African/Caribbean; two were Iraqi heritage and one was white. The participants were mostly long-standing members; ranging in length of relationship with MSH from two months (in the case of one asylum seeker) to over 20 years; with the majority having been members for 5 years or more.

We met on a total of six occasions; the introductory meeting, four focus groups, and on one occasion when only two participants were available, we held individual interviews. One focus group involved only the women of Pakistani/South Asian heritage, the other three focus groups were mixed with regard to gender and ethnicity. This mirrored how these South Asian women members routinely experience support within MSH. Focus groups and 
interviews were audio recorded, transcribed verbatim and data thematically analysed (Braun and Clarke 2006). The focus groups and interviews followed a topic guide exploring participants' views on: reasons for attending MSH; experiences of support (in MSH and other mental health services, and the relationship between MSH and NHS); connections between MSH, Liverpool 8, and the black community; matters of identity as a black or white person attending MSH; roles of MSH staff and peers; degree of involvement in MSH and suggestions for improvements. Participants all provided informed consent to take part, there confidentiality was assured, as was their right to withdraw at any time without detriment.

The research received ethical approval via the relevant University of Central Lancashire ethics committee (reference: PSYSOC 112).

As researchers exploring issues of belonging and identity, it is important to state that one of us is a Black African/Caribbean male of dual heritage and two of us are white British men with a Liverpool born 'Scouse' heritage (Mahatani, 2012). We appreciate the importance of reflexivity in the research process and as a prism by which we understood the participants, and they us, as men with different ethnicities and biographies some of which they may have identified with, and some not (Gunaratnam, 2003; Caballero, 2014). All three researchers are university academics, with prior knowledge of the work of MSH, and an interest in the value of alternative black mental health services, but independent of operational practices therein. We believe that this positioning allowed us to reflexively offer insightful contributions to analysis whilst remaining alert to risk of bias.

\section{Findings}

In the course of the analysis a substantial set of cross-cutting issues were identified in the service user accounts focused on the location of MSH within Liverpool 8 associated with appreciation for the services, including matters of access and negotiating experiences of stigma or problematic relations with mainstream services. It is these particular thematic 
concerns we focus upon in this paper, with the analysis including aspects of attachment to place, space and belonging. We describe these themes here and illustrate with selective quotes from participants. Some of the thematic material was more substantially reflective of members of African Caribbean heritage, particularly those offering more expansive accounts related to historical aspects of the local Black Community. Nevertheless, all participants offered affinities for place and space embodied in MSH that appeared independent of individual ethnicity. As such we present the themes as broadly representative of all members.

\section{Attachment to Liverpool 8}

For many, there was an obvious attachment to, identification with, and pride in the local community, and this was typically bound up with issues of place, ethnicity and heritage:

Yeah, the community, I've grown, grown up in Toxteth all my life ... This is Upper Parley [reference to Upper Parliament Street address], this is part of Liverpool 8 (Black/dual heritage man 1).

We like our area, it's got the most beautiful architecture, people come here to film ... we don't want concrete jungles and all that crap (Black /dual heritage woman 1).

I've got a black family, I've got history, I've lived round here for literally hundreds of years ... my great, great, grand, great great-grandmother's buried in Smithdown Road Cemetery (Black/dual heritage woman 2).

This attachment to Liverpool 8, was explained as a sense of belonging to an area that had a history; of struggle for people of African/(Caribbean) and dual heritage (African/Caribbean and white). The geographical place had been fought over and defended, across many generations: 
I don't know any black person whose kid has not been taken from the age of thirteen off the streets of Liverpool and had a good hiding from the Police. Show me one person of colour whose son has not been through that (Black/dual heritage woman 2).

Belonging and attachment to the area is wrapped up in experiences of racism and economic and social exclusions within the City as a whole. There is a sense of belonging, pride and ambivalence in the place of Liverpool 8, intrinsically linked with survival, staying power, and resistance, embodied by this participant's disposition:

Yeah, well that, you see my, my history, my personal history is in these streets, love them or hate them, that's, that's where I'm from. Yeah, I've been unemployed most of my life because I've lived round here basically, that's a fact (Black/dual heritage man 2).

This attachment to place can be nostalgic in tone, with a sense that the area has changed, and not necessarily for the better:

People have been moved out the area because of what happened [reference to the 1981 riots]. And the whole community's disintegrated, it's slowly, everyone's isolated (Black/dual heritage man 1).

There is a sense the 'Black community' as it was has changed with some gaining economic and social capital to move out of the area, leaving the most disadvantaged and vulnerable concentrated in Liverpool 8.

\section{MSH: A Space of Recognition and Belonging}


Participants' affinities for MSH, as a place in its own right, intersect with experiences of the space itself; the building, its unique character and the social relations therein. Relevant to this, observations were often juxtaposed with more critical feelings about other places and spaces within the psychiatric mainstream. It is that very sense of belonging for participants who reside in Liverpool 8 that makes MSH such an appealing and supportive place for those that attend the centre. It is a familiar setting, located in the heart of Liverpool 8 and, importantly, the space reflects the culture and heritage of the locality:

it was great, the staff were a mix and what I like about the staff here, when I was in (other place), a lot of the staff in there didn't have experience of everyday life (Black man 4).

This everyday life understates identification with experiences of rac(ism), class, poverty in places other than Liverpool 8 or MSH, such as the un-named mental health setting here. In contrast, MSH, is a place where ethnic and cultural difference is the norm. MSH staff reflect and embody this difference in terms of their own ethnic identity and their understanding, and connection to the Liverpool 8 area themselves. In this sense, the MSH space is more than its physical location; also comprising a set of relational interactions and milieu that have a character of mutual recognition, rather than experiences of exclusion and alienation felt elsewhere:

Some of the people that worked here I went to school with, they know me from when I was a, they've seen me get, knowing I've got ill, and never, never spoke to me different from when I was at school with them (Black/dual heritage man 2).

The sense of belonging is not only about place attachment, to Liverpool 8, but also to people; those who know the people who reside in and were brought up there. This is because the staff and service users of MSH both come from the area, and are aware of the struggle against racism, poverty and the institutions that have excluded the Black 
community for hundreds of years. To a large degree this awareness incorporates Liverpool's history as a port and a key site in the enslavement of Black people, but also importantly reflects more contemporary discriminations; in the Liverpool labour market for instance. There is affirmation that to belong here, in many ways you need to be authentically local, to understand what the Black community means to people and how this is associated with particular experiences that have a context pertaining to race, class, place and space. There is an unspoken, taken for granted, understanding about commonplace aspects of the struggle that community residents and members of MSH experience, and this is felt to both resonate with, and be reciprocated by, the staff:

Apart from that it is a place, where if you are ethnic person, you feel comfortable. You are not the only black face are you? (Black/dual heritage woman 2).

These accounts are interesting because time, place and race are foregrounded. Being a part of the Liverpool 8 community is, in part, an identification with having a heritage there, a history within the community, with a family that has struggled because of racism within the city of Liverpool; and to understand this you need to be Black or connected to the black community in some way. History, place and race become defining characteristics of a sense of belonging to the everyday experience of $\mathrm{MSH}$.

Yet, paradoxically, though race is important, white people are also seen as welcome in MSH. This is in part due to the significant population in Liverpool 8 that are of mixed (dual heritage) and in mixed relationships. If white people cross the line, and become part of the Black community, through marriage, or identifying with people of colour and their struggle against racism in the area, then they become part of the community understood as Liverpool 8:

See the area is made up of many different peoples isn't it? They can't put it down to a black thing. We are Irish, we are everything aren't we? We are Chinese, Asian (Black/ dual heritage man 1). 
For these participants, being Black in Liverpool 8 acknowledges realities of multi ethnic relationships, and the white people who are part of these Black families have also been part of struggles against racism. There is an acknowledgement that Black identity is inclusive within the Liverpool 8 community and this spirit of an inclusive understanding of Blackness in its broadest sense is a defining experience of members who attend MSH:

I've lived in this area all my life, don't know nowhere else, I've always lived with people of different colours, different nationalities ... Different religions and this centre reflects that for me... And there's such mixtures of people, if they ever get round to telling you (Black/dual heritage man 2).

You feel like you belong here (South Asian woman 6)

\section{A Safe Haven}

The particular difficulties that participants articulated as BAME people who had experienced mental distress created conditions where racism and the punitive elements of the mental health system converge. MSH is seen as a constant support, a port in the storm:

I come here to get away. It's nice and quiet and peaceful. I can feel safe (South Asian woman 4)

This sense of sanctuary also guards against oppressive experiences and concerns over stigma within the community:

I wouldn't tell my family, I wouldn't tell the neighbours, I can speak free to the staff, to the members and it's great that, because it gives you an outlet, saves it building up and building up, but I, I mean like most people really I think I can only talk about Mary Seacole House because this is where I attend, is a safe haven for many people (Black man 4). 
Despite trauma and pain participants have experienced due to mental distress and encountering the mental health system, they felt safe and secure attending MSH and relating to the staff. In contrast to family and neighbours, MSH staff were prepared to listen. Quite literally, they provided a safe haven for members. It is an understanding, an empathy that is located within this safe space that provides the participants with a sense of belonging. Where the pain of mental distress, isolation and racism converge for some participants, MSH provides a protected space. This participant explains how she feels able to be herself without disapproval. Whilst the pain and stigma of experiencing mental distress is all too evident amongst those people she knows, MSH is always a place where she can feel safe and listened to:

there's no judgement passed on you here, there's no stigma ... when I was labelled, when I was diagnosed with schizophrenia, all of a sudden that word seems to strike terror into people, you find so-called friends disappear into the woodwork (Black woman 2).

Similarly, for this participant there is an inclusive, friendly quality to relationships in MSH:

They don't treat us like service users, they treat us like friends and any problems you have you can ask them or they'll relay information or do research for you to just get the problem solved (Black/dual heritage man 5).

This is an interesting distinction that hints at issues of power, such that MSH members feel respected and treated equally, as friends, by fellow members and staff who have in many cases grown up together. The notion of service user, a term developed to engender respect for people that access social care, is rejected. Somewhat ironically, language coined ostensibly in a spirit of empowerment is actually experienced as disempowering, by creating a distance between staff and those that use mainstream services where this terminology is more prominent. Thus, the term 'Member' of MSH implies an equality of relationship, based on biography, mutuality, race, place and space.

\section{Mental distress does not discriminate}


All of the participants talked about the indiscriminate pain of mental distress in their lives, how family and friends may shun them, compounding feelings of desperation and loneliness, yet emphasise common ground amongst peers:

... the anxiety, the later depression, it's, it's fearfulness and when you're alone, er, you imagine all kinds of stuff, so when you come out to Mary Seacole House you're away from all that ... you're not listening to your own thoughts ... it's, you, you're listening to other people and they're, listen to other people's problems and you think ... people to be, you know, worse than what you are about, you know, and it sort of like, it puts you in perspective (Black man 5$)$.

MSH staff create an atmosphere based on values of cultural diversity and inclusivity. As this participant explains, inclusivity is important because mental distress affects all people:

to be truthful for me, the most important thing, the reason I kept coming here was because it was a mix of people, of black and white, because, you know, as I see it, mental illness it doesn't discriminate (Black/dual heritage woman 2).

The isolation and stigma felt by people who experience mental distress is not unique to this community. However, it is the sense of community, in the face of difficult and debilitating times that underpins support within the space of $\mathrm{MSH}$.

\section{Discussion}

The participants' accounts consistently refer to notions of place; affinities for the locality of Liverpool 8, the distinct place that is MSH within it, and perceived and actual changes to these places. In such a context, place attachment can be an important factor in resilience to 'psychological threats that can arise when changes to a place threaten people's identities' (Anton and Lawrence 2014: 460). MSH members face double discrimination threats regarding race and mental health. Pinfold (2000: 210) questions whether communities are ready to be inclusive rather than discriminatory, whether society can or wishes to care for people stigmatised by involvement in the mental health system. She argues for 'safe spaces' 
to be built 'for, and with, mental health service users and their "unorthodox normalities". African/Caribbean users of the mental health system have argued that Black mental health services create such places of safety, replete with sense of belonging; a port in a storm, whilst all outside is turbulence and anxiety (BME Voices, 2018; Francis 1991).

\section{Race, place and space}

MSH was founded by Black community activists amidst wider struggles taking place concerning race in the city and trenchant national and local critique of racial anomalies in experiences of care and treatment. This foundational activism established an historical, emotional, and physical legacy in the space occupied by MSH (Gifford, Brown and Bundyl 1989, MSH 2012). Similarly, Kalathil et al's (2011: 9) study of BAME experiences in relation to mental health care also identified the importance of:

overcoming the effect of negative social experiences, developing mechanisms to cope with societal oppression, attaining a shared sense of identity and social justice through collective action, and having access to 'recovery spaces' where specific sociocultural aspects of distress could be safely addressed.

The precise location of MSH on Upper Parliament Street, near the epicentre of the riots, has significant pyschosocial resonance for the community (Christian, 2008; Boland 2010) and BAME survivors of the mental health system. It is synonymous with the struggle against racism within the mental health system and the Black community reclaiming control over collective and individual mental health, partly as a response to psychological impacts of racism (Gajwani et al. 2016, Singh et al. 2007). When participants articulate their rootedness and affinity with the streets of Liverpool 8, MSH is identified as a focal point of resistance to over-incarceration of BAME people within the mental health system, within an emotional and political connection with race, place and space (Pinfold 2000; Small 1991). There is also pyschosocial reassurance of a safe place, where members can be themselves, as Black people and survivors of the mental health system. 
The safety and security that MSH members expressed manifested itself in two ways. The Place of Liverpool 8 and the Space of MSH were both joined in resistive struggles alongside BAME mental health users, yet separately. Whilst some feel judged within the Black community (as is often the case in wider society), sanctuary is found when they visit MSH. This unique Space allowed members to be themselves regardless of ethnicity or mental health status, providing protection the daily debilitating effects of racism, stigma and exclusion.

\section{Identity and Belonging}

The participants in this study voiced affinities for MSH that were strongly associated with a sense of belonging. This identified with, and was representative of, the long established Black community. But, it also reflected a sense for Black mental health survivors that MSH provides more than a generic mental health service. There is an understanding that vulnerable and disadvantaged members are more welcome and less alienated when relating to staff from a similar ethnic, cultural and spatial background, who look and sound like them; with belonging and trust negotiated via matters of identity and recognition (author's own 2010; 2012; 2013). The participants clearly associated the effect of racism on their lives with affinities for MSH staff, feeling supported in circumstances of mutual recognition; by people who are the same as them, look like them, in some cases went to school with them, and have similarly experienced racism. Thus, identity and belonging form a buffer against the psychosocial detriment of racism (Christie and Hill 2003; author's own; 2012).

We suggest a concept of placism as potentially helpful for understanding complexities of identity and experience in participants' accounts. Notions of place and space converge in the marginalised lives of MSH members within the community of Liverpool 8 and wider interpretations and experience of racism in the city and the UK as a whole. There were two intersecting commonalities in participants' experiences; racism and mental health needs (Crenshaw 2019; Nayak and Robbins 2018). Whilst racism and discrimination have caused generations of pain and exclusion, the isolation of experiencing mental health difficulties and punitive responses of the mental health system seemingly did not discriminate. Whatever their ethnicity, whether they were black or white, and/or had other intersecting 
identities, they had all experienced the pain of rejection and stigma from (some of) their friends, immediate family and the wider community (Nayak and Robbins 2018).

In a simple sense, placism might describe prejudice against a particular place, such as in contemplation of Liverpool 8's standing within the city as a whole. In this context, however, it gives a name to the intersecting and contradictory exclusions occurring at the nexus between racism and discrimination experienced by survivors of the mental health system. We should also note that this survivor identity, and attendant consequences, need not be singular, and may include other intersecting identities, for instance gender, sexuality, class or disability, as they also relate to place (Robins 2018; Siddiqui and Thiara, 2018). These place-identified exclusions are contradictory in also allowing for contemplation of place centric solutions, such as MSH, as well as certain negative aspects attendant on affinities for particular places. It is the very denial of humanity, and the debilitating impact on BAME mental health users' daily experience that leads them to seek solace and belongingness in the safe spaces within MSH as a place. As Black Spaces suggest, it is the security of a place that empathises and viscerally understands the racism BAME survivors experience which explains their appreciation for MSH (Christie and Hill 2003).

As this study was a small-scale qualitative inquiry within one alternative mental health facility situated within a place where we have drawn attention to some unique contextual circumstances, matters of generalisability of the findings are open to question. That said, there are a number of such alternative mental health services, and we might expect the relationships between place, space and experience within these to share some commonalities. Moreover, more general issues of place and discrimination within wider mental health services and society at large may, at least in part, be illuminated with recourse to some of our findings. Arguably, some of the more powerful aspects of our findings are associated primarily with participants of African Caribbean heritage and residents more typically connected to the history of the Liverpool Black Community; albeit with the caveat that inclusion in The Community does not necessarily depend upon rigid ethnic criteria, and also includes individuals identified as white. That said, questions remain 
regarding how relevant the importance of Liverpool 8 in the City's Black history is to different ethnic groups and genders, and precisely how affinities for and experiences of place and space are worked out. Further research might fruitfully finesse the differences of viewpoint associated with particular ethnic groups, especially in the light of contemporary changes of residency and service usage reflecting recent waves of immigration, including those seeking asylum. The Kalathil et al. (2011) study, for example, included African Caribbean and South Asian participants but reporting of findings does not disarticulate ethnicity.

For all ethnicities in our study, the only place that the participants felt they belonged was in the culture and fabric of the multi ethnic community of Liverpool 8 (Boland, 2008; Lashlau 2015). Similarly, in terms of experiencing mental health support, they only experienced belonging in spaces provided within $\mathrm{MSH}$, with particular emphasis upon feelings of safety and sanctuary. As mental health survivors their experience of placism is a metaphor for the wider fractures and schisms that rac(ism) manifests in the UK today. This turbulent contemporary context is replete with exclusionary, place-resonant binaries (Rajan-Rankin, 2015): Us and Them, Insiders and Outsiders, White and Black - my place, their place, our space, theirs. Through sharing their experiences of placism and the refuge that MSH can provide, participants simultaneously provide portents of (for us, undesirable) things to come and how to imagine more supportive, protective alternatives.

\section{Conclusion}

This study demonstrates that individuals still experience an often punitive and unforgiving mental health system and wider society. Conversely, there is a shared cultural heritage, an ethnic and political identity that they are proud to be a part of. Notions of place are hugely salient to making sense of this and imagining alternatives. Histories of intersectional rejection have led to the development of self-organised alternatives for enabling support. One such alternative resource centre, MSH, provides a place and space for members to feel safe, confident and to grow as individuals. It is the intersection, of race, a safe space and the opportunity of peer support and self-help, that is the very life blood of MSH. 


\section{References}

Amin, A. (2008). Collective culture and urban public space, City: analysis of urban trends.

Culture, Theory, Policy, Action, 12:1, 5-24. https://doi.org/10.1080/13604810801933495

Amin, A. (2002). Ethnicity and the Multi-Cultural City: Living with Diversity. Environment and Planning 34: 959-980. https://doi.org/10.1068/a3537

Anton, C. \& Lawrence, C. (2014). Home is where the heart is: The effect of place of residence on place attachment and community participation. Journal of Environmental Psychology, 40, 451-461. http://dx.doi.org/10.1016/j.jenvp.2014.10.007

Author's own 2001

Author's own 2010, 2012 and 2013

Becares, L. \& Nazroo, J. (2013). Social capital, ethnic density and mental health among ethnic minority people in England: a mixed-methods study. Ethnicity \& Health, 18, 544-562. https://doi.org/10.1080/13557858.2013.828831

Belchem, J. (2006). Merseypride: essays in Liverpool exceptionalism. Oxford: Oxford University Press.

Ben-Tovim, G., Gabriel, J., Law, I. \& Stredder, K. (1986). A political analysis of local struggles for racial equality. In J. Rex \& D. Mason (eds) Theories of Race and Ethnic Relations. Cambridge: Cambridge University Press. pp.131-152.

Ben-Tovim, G., Gabiel, J., Law, I. \& Stredder, K. (1986). The local politics of race. London: Macmillan. 
Ben-Tovim, G. (1997). Why "positive action" is politically correct. In Modood T. and Werbner P. (eds) The Politics of Multiculturalism in the New Europe. Racism Identity and Community. London: Zed Books. pp209-223

Bernardo, F. \& Palma-Oliveira, J. M. (2005). Place change and identity processes. Medio Ambiente y Comportamiento Humano, 6, 71-87. http://hdl.handle.net/10174/4675

Beynon, H. (1984). Working for Ford. Harmondsworth: Penguin.

Bhui, K., Ascoli, M. \& Nuamh, O. (2012). The place of race and racism in cultural competence: What can we learn from the English experience about the narratives of evidence and argument? Transcultural psychiatry, 49(2), 185-205. https://doi.org/10.1177/1363461512437589

Bhui, K., Ullrich, S., Kallis, C. \& Coid, J.W. (2015). Criminal justice pathways to psychiatric care for psychosis. The British Journal of Psychiatry, 207(6), 523-529. https://doi.org/10.1192/bjp.bp.114.153882

BME Voices (2019) BME Voices webpages. Retrieved from www.bmevoices.co.uk/ Boast, N. \& Chesterman, P. (1995). Black people and secure psychiatric facilities: Patterns of processing and the role of stereotypes. British Journal of Criminology, 35: 218-35. https://doi.org/10.1093/oxfordjournals.bjc.a048495

Boland, P. (2008a). "Capital of Culture - you must be having a laugh" Challenging the official rhetoric of Liverpool as the 2008 European cultural capital. Social and Cultural Geography, 11(7), 627-645. https://doi.org/10.1080/14649365.2010.508562

Boland, P.(2008b). The construction of images of people and place: Labelling Liverpool and stereotyping Scousers. Cities, 25, 355-369. doi:10.1016/j.cities.2008.09.003 
Boland, P. (2010). Sonic geography, place and race in the formation of local identity: Liverpool and Scousers. Geografiska Annaler: Series B, Human Geography, 92(1), 1-22. https://doi.org/10.1111/j.1468-0467.2010.00330.x

Braun, V. \& Clarke, V. (2006). Using thematic analysis in psychology. Qualitative Research in Psychology, 3(2), 77-101. DOI: 10.1191/1478088706qp063oa

Brown, G. G., Reed, P. \& Harris, C. C. (2002). Testing a place-based theory for environmental evaluation: an Alaska case study. Applied Geography, 22(1), 49-76.

https://doi.org/10.1016/S0143-6228(01)00019-4

Caballero, C. (2014). Mixed emotions: Reflections on researching racial mixing and mixedness. Emotion, Space and Society, 11, 79-88.

https://doi.org/10.1016/j.emospa.2013.07.002

Care Quality Commission (2018). Monitoring the Mental Health Act: 2016 to 2017. The eighth annual report by the Care Quality Commission on the use of the Mental Health Act 1983. Newcastle: CQC.

Chen, E., Harrison, G. \& Standen, P. J. (1991). Management of first episode psychotic illness in Afro-Caribbean patients. The British Journal of Psychiatry 158, 517-522. https://doi.org/10.1192/bjp.158.4.517

Christian, M. (2008). The Fletcher report 1930: a historical case study of contested black mixed heritage Britishness. Journal of History and Sociology, 21, 213-241. https://doi.org/10.1111/j.1467-6443.2008.00336.x

Christie Y. \& Hill N. (2003). Black Spaces Project. London: The Mental Health Foundation. 
Cooperrider, D. L. \& Srivastva, S. (1987). Appreciative inquiry in organizational life. In Woodman, R. W. \& Pasmore, W.A. Research in Organizational Change and Development. Vol. 1. Stamford, CT: JAI Press. pp129-169.

Crenshaw K. (2019). On Intersectionality: Essential Writings. New York: New Press.

Department of Health (2005). Delivering race equality in mental health care: an action plan for reform inside and outside services, and; The government's response to the independent inquiry into the death of David Bennett. London: Department of Health.

Department of Health and Social Care (2018). Modernising the Mental Health Act - final report from the independent review. London: DHSC.

Fernando, S. (2005). Multicultural mental health services: projects for minority ethnic communities in England. Transcultural Psychiatry, 42, 420-436. https://doi.org/10.1177\%2F1363461505055624

Fernando, S. (2010). Mental health race and culture. $3^{\text {rd }}$ ed. Houndmills: Palgrave Macmillan

Francis E. (1991). Racism and Mental Health. Some causes for concern for Social Work.' Chapter 10 in Setting the Context for Change. Leeds: CCETSW

Fried, M. (2000). Continuities and discontinuities of place. Journal of Environmental Psychology, 20(3), 193-205. https://doi.org/10.1006/jevp.1999.0154

Gajwani, R., Parsons, H., Birchwood, M. \& Singh, S.P. (2016). Ethnicity and detention: are Black and minority ethnic (BAME) groups disproportionately detained under the Mental 
Health Act 2007? Social Psychiatry and Psychiatric Epidemiology, 51(5), 703-711. https://doi.org/10.1007/s00127-016-1181-z

GCMHG (2018). Annual Report 2017/18. Liverpool: Mary Seacole House.

Gifford, A. M., Brown W., Bundy R. (1989). Loosen the Shackles. London: Karia Press.

Gudjonsson G.H., Rabe-Hesketh S. \& Wilson C. (2000). Violent incidents on a medium secure unit: the target of assault and the management of incidents. The Journal of Forensic Psychiatry 11(1), 105-118. https://doi.org/10.1080/095851800362391

Gunaratnam Y. (2003). Researching 'Race' and Ethnicity. London: Sage.

Hall, S. (1998). Cultural identity and diaspora. in Rutherford, J. (ed.) Identity: community, culture, difference. 2nd edn. London: Lawrence and Wishart. pp. 222-237.

Harris, P. B., Werner, C. M., Brown, B. B. \& Ingebritsen, D. (1995). Relocation and privacy regulation: A cross-cultural analysis. Journal of Environmental Psychology, 15(4), 311-320. https://doi.org/10.1006/jevp.1995.0027

Henfrey, J. (1981). A history of race and racism in Liverpool, 1660-1950. Liverpool: Merseyside Community Relations Council.

Kalathil, J., Collier, B., Bhakta, R., Daniel, O., Joseph, D. \& Trivedi, P. (2011) Recovery and Resilience: African, African-Caribbean and South Asian women's narratives of recovery from mental distress. London: Mental Health Foundation.

Lashua, B. (2015). Mapping the politics of 'race', place and memory in Liverpool's popular music heritage. In S. Cohen, R. Knifton, M. Leonard \& L. Roberts (eds) Sites of popular music heritage: memories, histories, places. New York: Routledge. pp. 45-61.

Law, I. \& Henfrey, J. (1981). A history of race and racism in Liverpool, 1660-1950. Liverpool: Merseyside Community Relations Council. 
Leese, M., Thornicroft, G., Shaw, J., Thomas, S., Mohan, R., Harty, M.A. \& Dolan, M. (2006). Ethnic differences among patients in high-security psychiatric hospitals in England. The British Journal of Psychiatry, 188(4), 380-385. https://doi.org/10.1192/bjp.188.4.380

Littlewood, R. \& Cross, S. (1980). Ethnic minorities and psychiatric services. Sociology of Health \& Illness, 2, 194-201. https://doi.org/10.1111/1467-9566.ep10487792

Liverpool Black Caucus (1986). The racial politics of Militant in Liverpool: the black community's struggle for participation in local politics 1980-1986. Liverpool: Merseyside Area Profile Group and Runnymede Trust.

Low, S. M. \& Altman, I. (1992). Place attachment: A conceptual inquiry. In I. Altman \& S. M. Low (Eds.), Place attachment. New York: Plenum Press. pp. 1-12

Mahtani, M. (2012). Not the same difference: notes on mixed-race methodologies. In: R. Edwards, S. Ali, C. Caballero \& M. Song (Eds.), International perspectives on racial and ethnic mixing and mixedness. London: Routledge.

Marcheschi, E., Laike, T., Brunt, D., Hansson, L. \& Johansson, M. (2015). Quality of life and place attachment among people with severe mental illness. Journal of Environmental Psychology, 41, 145-154. https://doi.org/10.1016/j.jenvp.2014.12.003

Mesch, G. S., \& Manor, O. (1998). Social ties, environmental perception, and local attachment. Environment and Behavior, 30(4), 504-519. https://doi.org/10.1177\%2F001391659803000405 
Moodley, P. \& Thorneycroft, G. (1988). Ethnic group and compulsory detention. Medicine, Science and the Law, 28, 324-328. https://doi.org/10.1177\%2F002580248802800412

Morgan, C., Mallett, R., Hutchinson, G. \& Leff, J. (2004). Negative pathways to psychiatric care and ethnicity: the bridge between social science and psychiatry. Social Science and Medicine, 58, 739-752. https://doi.org/10.1016/S0277-9536(03)00233-8

Nayak, S, \& Robbins, R. (2018). Intersectionality in social work: activism and practice in context. London: Routledge.

NIMHE (2003).Inside outside: improving mental health services for black and minority ethnic communities in England. London: NIMHE.

Paradies, Y., Ben, J., Denson, N., Elias, A., Priest, N., Pieterse, A., Gupta, A., Kelaher, M. \& Gee, G. (2015). Racism as a determinant of health: a systematic review and meta-analysis. PloS one, 10(9), p.e0138511. https://doi.org/10.1371/journal.pone.0138511

Parr, H. (2000). Interpreting the 'hidden social geographies' of mental health: ethnographies of inclusion and exclusion in semi-institutional places. Health and Place, 6(3), 225-237. https://doi.org/10.1016/S1353-8292(00)00025-3

Parr, H. (1997). Mental health, public space, and the city: questions of individual and collective access. Environment and Planning D, 15, 435-454. https://doi.org/10.1068\%2Fd150435

Pinfold, V. (2000). 'Building up safe havens... all around the world': users' experiences of living in the community with mental health problems. Health and Place, 6(3), 201-212. https://doi.org/10.1016/S1353-8292(00)00023-X 
Proshansky, H. M., Fabian, A. K. \& Kaminoff, R. (1983). Place identity: physical world socialization of the self. Journal of Environmental Psychology, 3, 57-83. https://psycnet.apa.org/doi/10.1016/S0272-4944(83)80021-8

Rajan-Rankin, S. (2015). Anti-racist social work in a 'post-race society'? Interrogating the amorphous 'other'. Critical and Radical Social Work, 3, 207-220. https://doi.org/10.1332/204986015X14286590888439

Raleigh, V., Irons, R., Hawe, E., Scobie, S., Cook, A., Reeves, R., Petruckevitch, A. \& Harrison, J. (2007). Ethnic variations in the experiences of mental health service users in England. Results of a national patient survey programme. British Journal of Psychiatry 191, 304-312. https://doi.org/10.1192/bjp.bp.106.032417

Rogers, A. \& Faulkner, A. (1987). A place of safety, London: MIND Publications.

Sainsbury Centre (2010). An evaluation of mental health service user involvement in the re-commissioning of day and vocational services. London: Sainsbury Centre.

Sass, B., Moffat, J., Bhui, K. \& McKenzie, K. (2009). Enhancing pathways to care for black and minority ethnic populations: a systematic review. International Review of Psychiatry, 21, 430-438. https://doi.org/10.1080/09540260802204121

Seebohm, P, Henderson, P, Munn-Giddings, C., Thomas, P., Yasmeen, S. (2005) Together we will change: Community development, mental health and diversity. London: Sainsbury Centre for Mental Health.

Singh, S.P., Greenwood, N.A.N., White, S. \& Churchill, R. (2007). Ethnicity and the Mental Health Act 1983: systematic review. The British Journal of Psychiatry, 191, 99-105. https://doi.org/10.1192/bjp.bp.106.030346 
Small, S. (1991). Racialised relations in Liverpool: A contemporary anomaly. Journal of Ethnic and Migration Studies, 17(4), 511-537. https://doi.org/10.1080/1369183X.1991.9976265

Stokols, D. \& Shumaker, S. A. (1982). The psychological context of residential mobility and well-being. Journal of Social Issues, 38(3), 149-171. https://doi.org/10.1111/j.15404560.1982.tb01776.x

Taaffe, P. \& Mulhearn, T. (1988). Liverpool: a city that dared to fight. London: Fortress.

Tartaglia, S. (2013). Different predictors of quality of life in urban environments. Social Indicators Research, 113, 1045-1053. https://doi.org/10.1007/s11205-012-0126-5

Thomas, P. (2014). Psychiatry in context: Experience, meaning \& communities. Wyastone Leys, PCCS Books.

Thomas, P., Seebohm, P., Henderson, P., Munn-Giddings, C. and Yasmeen, S. (2006). Tackling race inequalities: community development, mental health and diversity. Journal of Public Mental Health, 5(2), 13-19.

Torkington, N.P.K. (1983). The racial politics of health: A Liverpool profile. Merseyside Area Profile Group, Liverpool: University of Liverpool.

Wallcraft, J. Read, J. \& Sweeny, A. (2003). On our own terms: users and survivors of mental health services working together for support and change. London: The Sainsbury Centre for Mental Health.

Walker, R. J., Williams, J. S. \& Egede, L. E. (2016). Influence of race, ethnicity and social determinants of health on diabetes outcomes. The American Journal of the Medical Sciences, 351(4), 366-373. https://doi.org/10.1016/j.amjms.2016.01.008 
Wolch, J. \& Philo, C. (2000). From distributions of deviance to definitions of difference: past and future mental health geographies. Health and Place, 6(3), 137-157. https://doi.org/10.1016/S1353-8292(00)00019-8

Wright S. \& Hutnik N. (2004). Black Spaces Project. London: Mental Health Foundation.

Zack-Williams, A. B. (1997). African diaspora conditioning: The case of Liverpool. Journal of Black Studies, 27(4), 528-542. https://doi.org/10.1177\%2F002193479702700405

Ziersch, A. M., Baum, F. E., MacDougall, C. \& Putland, C. (2005). Neighbourhood life and social capital: the implications for health. Social Science \& Medicine, 60(1), 71-86. https://doi.org/10.1016/j.socscimed.2004.04.027 